15e Conference internationale du tournesol (Toulouse, 13-15 juin 2000) - Physical refining of sunflower oil

\title{
Physical refining of sunflower oil
}

Oléagineux, Corps Gras, Lipides. Volume 7, Numéro 4, 305-8, Juillet - Août 2000, La filière, aujourd'hui, demain

Auteur(s) : Katalin KOVARI, Jean DENISE, Zsolt KEMENY, Katalin RECSEG, .

Summary: Physical refining has several advantages compared to the classical chemical one. This process is more economical (improved yield, lower investment cost, less chemicals used) environmental friendly process (no soapstock to be treated, splitted) but more sensitive to the crude oil quality. Physical refining of sunflower oil is discussed in details. Recent developments in the field of processes, equipment and control have made it possible to refine by physical way the high phosphatide containing seed oils as well. Special degumming processes, improved performance of bleaching materials, better design of deodorizers are applied in new installations; huge capacity oneline physical refineries are successfully operated in different countries.

Keywords: sunflower oil, physical refining.

\section{ARTICLE}

In the last decade significant improvement has been done in the field of oil refining techniques as well as in that of packaging techniques. This trend ended up in decrease of industrial cost, improvement of quality and better protection of environment. Development of processes, equipment and process control made possible to apply high-capacity, one-line physical refinery with advanced automatization, on-line control [1].

Physical refining has several advantages compared to classical chemical one:

- improved yield;

- lower investment costs;

- less environmental impact (no soapstock to be treated, less waste water formed);

- mild refining (less chemicals used);

but this process is more sensitive to the crude oil quality. A flow sheet of chemical and physical refining processes is shown on figures 1 and 2, respectively.

Applying physical refining means increased importance of pretreatment before distillative removal of the free fatty acids. 
One should ensure to eliminate phospholipids reaching less than $10 \mathrm{mg} / \mathrm{kg} P$ content after degumming and less than $4 \mathrm{mg} / \mathrm{kg}$ after bleaching, and the same time to reduce iron and copper content below $0.1 \mathrm{mg} / \mathrm{kg}$ and $0.01 \mathrm{mg} / \mathrm{kg}$ respectively. Sunflower oil has a high nutritional value, having $62-70 \%$ linoleic acid content (essential fatty acid) but, on the other hand, this high polyunsaturated fatty acid content makes this oil sensitive to oxidation.

Crude sunflower oil which has reached a certain level of oxidation, is difficult to refine. There are two main difficulties:

- removal of non-hydratable phospholipids/iron;

- and sometimes when the autooxidation has really gone too far fix colour formation, which is not removable by bleaching and/or heat bleaching.

As the crude sunflower oil contains - as a minor component - natural antioxidant (tocopherol 700$1,000 \mathrm{mg} / \mathrm{kg}$ ) usually there is no autooxidation problem except in the case of extreme non-proper storage - transport conditions.

\section{Degumming processes}

In the last two decades a series of inventions have been implemented to the industrial practice (process and equipment as well) mainly in the field of degumming giving operators the chance for thex to choose the most economical and environmental friendly physical refining in the new installation. The efficient removal of phosphatides is the keypoint in physical refining.

Vegetable oils contain phospholipids, which have to be removed during the process. Phospholipids (also called phosphatides) are phosphoric acid diesters of glycerol and the phosphoric acid in the molecule is esterified by an alcohol (choline, ethanolamine) or a polyol (inozitol). In phosphatidyl acid the phosphoric acid moiety is not linked to any alcohol or polyol. While phosphatidyl choline (PC) and phosphatidyl inozitol (PI) are completely hydratable, the phosphatidyl ethanolamine (PE) is only partially and phosphatidyl acid (PA) is non hydratable, when they form salt with divalent cations $\left(\mathrm{Ca}^{++}, \mathrm{Mg}^{++}\right)$or when they are in non-dissociated forms. The efficient degumming process should convert the non-hydratable phosphatides to hydratable ones and remove by hydrating and separation.

The simplified chemistry is the following:

- the phosphatide/metal complexes are decomposed by acid addition;

- the phospholipids, which are formed to be hydratable in this way are hydrated by adding water;

- partial neutralization and/or cooling is applied to avoid migration of phosphatides back to the oil phase;

- the holding time helps to agglomerate the phosphatides for their easier removal.

Usually, citric acid is used not only to decompose the metal salt, but as a chelating agent to keep the metals in a water-soluble complex. In industrial applications, UF degumming (Cereol), 
superdegumming, unidegumming (Unilever) TOP degumming (Vandemoortele), and Enzymax (Lurgi) patents are used [1-4, 6-8].

SOFT degumming (Tirtiaux) is under development [5]. Each of them ensures sufficient low remaining $P$ content, but certainly there are differences in special equipment need and/or chemicals need. The enzymax process uses phospholipase $A_{2}$ for converting non-hydratable phosphatides to lysophosphatides, which are more soluble in water phase. For SOFT process EDTA, as a chelating agent is used (for a detailed description of core of the processes see table).

\section{Predewaxing}

Crude sunflower oil contains waxes, which are long chain fatty acid ester with long chain alcohol $\left(\mathrm{C}_{44}\right.$ - $\mathrm{C}_{60}$ ). These waxes crystallise at room temperature and cause "turbidity" in the refined oil. That is why it is necessary to remove them in order to produce "bright oil". The classical way is to cool down the oil in order to allow wax crystallisation and to filter the crystals out. Because of the clogging effect of the waxes, this cold filtration is carried out in the presence of filter aid (perlite or diatoma). This operation has a very negative effect on refining costs, since it needs $1 \mathrm{~kg}$ of filter aid/ton of oil for each $100 \mathrm{ppm}$ of waxes. Moreover, this technology decreases tremendously the refining yield, since $1 \mathrm{~kg}$ of fat is lost for $1 \mathrm{~kg}$ of filter aid used. So, as with chemical refining, where predewaxing is combined with the neutralization to remove the majority of the waxes (Alfa Laval process), in physical refining, the degumming step can be combined with predewaxing. Most of the abovementioned processes also involve predewaxing in the case of sunflower oil processing, reducing the wax content to $100-150 \mathrm{mg} / \mathrm{kg}$. This makes the post dewaxing (filtration) process easier and cheaper.

\section{Bleaching}

In the case of physical refining, bleaching has an increased importance for the further removal not only of plant colouring materials but of phosphatides and metals as well.

To reduce the bleaching earth consumption it is not only a question of the economy of the process but also the question of the solid waste production (environmental impact, disposal). A wide range of new highly activated bleaching earths and synthetic silica products are available on the market (used alone or in combination). Synthetic silica products have a 4-6 times higher adsorption capacity for phosphatides, metals, soap than the bleaching earths, but have no effect on the plant colourings [10].

New techniques like countercurrent bleaching and electrofiltration (ÖHMI) are under development [11].

Purchasing crude sunflower oil (or seed) from certain countries involves the risk of PAHs (polyaromatic hydrocarbons) contamination, originated from direct fuel gas drying of the seeds or from environmental pollution. PAHs (like benzo-a-pyrene) are carcinogenic and should be removed during refining. The use of activated carbon in the bleaching step is the only solution to remove heavy PAHs (example of PAHs removal, figure 3). 


\section{Deacidification - desodorization}

The high temperature steam (or nitrogen) distillation under very low remaining pressure (1-2 mbar) is the core process in physical refining. From the well pretreated oil the free fatty acids are removed by distillation and in the same equipment the volatile flavour and smell compounds, oxidative by products, pesticides and light PAHs are also removed. The finished product has a neutral taste and smell, a light colour and a long shelf life. In the last decade, more and more attention has been paid to the risk of trans izomer fatty acid formation during this refining step.

Nutritional studies have reported that trans monoene izomer fatty acids are as "bad" as saturated fatty acids in the diet concerning the risk of cardiovascular diseases.

Margarine producers are offering "trans-free" margarine products, in which the total trans fatty acid content is declared to be below $1 \%$. So liquid oil producers should deliver fully refined oil with less than $1-1.5 \%$ total trans for sunflower and rape respectively. Another, more strict demand is more specific for the fatty acid composition of the oil, so the degree of izomerization (DI) should be max. 5$10 \%$ of the total $C_{18: 3}$ and max. $0.7-1 \%$ of the total $C_{18: 2}$.

The trans izomer formation kinetics has been studied under deodorization conditions. The trans izomer formation has been proved to follow first order kinetics, depending on the temperature and time. The linolenic acid has 13-14 times more sensitivity to the trans formation than the linoleic acid (figure 4) [11].

In the frame of an EU-funded FAIR project, Cereol and Lesieur R\&D Laboratory have carried out a laboratory and pilot test and as a result a kinetic model has been established and validated at pilot scale level [12-14].

Using this kinetic model the trans izomer formation can be predicted for each deso conditions.

The figure 5 shows the calculated theoretical values. It is clear from this calculation that mild condition, e.g. keeping the temperature below $240^{\circ} \mathrm{C}$, is necessary to meet the requirement of low trans fatty acid content. The design of the deodorizer is also important. Any hold up and/or local overheating can cause higher izomerization degree than the prediction from the model.

The constructors of deodorizers follow the trend and propose a new generation of deodorizers with special design (packed column deodorizer, deodorizer with stripper) [17].

To carry out effective removal of free fatty acids at the proposed temperature it is absolutely necessary to produce high vacuum. The conventional steam ejectors produce quite a high amount of waste water. The recent developments in this field have combined the mechanical vacuum pump with steam ejectors using indirect cooler to reduce the waste water.

The most sophisticated and environment - friendly solution is the ice - condensing system, which is completely closed and produces as much as waste water equal to the amount of direct steam used, while eliminating all the smell problems too [15]. 


\section{Nitrogen saturation-bottling}

The sunflower oil is sensitive to oxidation, that is why it is very important to protect it. The best solution is to saturate it with nitrogen gas just after cooling the oil (before leaving the deodorizer). The dissolved nitrogen protects the oil against oxygen diffusion. The nitrogen saturation is also essential to keep the bottled oil in good shape.

With the really high innovations in the last decade in the field of packaging machines, the PET bottles/caps close completely airtight. The weight of the bottles decreases gradually, reducing PET usage and logistic costs. The lighter the bottle, the higher risk of deformation caused by improper nitrogen saturation.

\section{By-products utilization}

During deodorization/deacidification a part of the unsaponifiable matter (like tocopherols, sterols, and sterolesters) are distilled out together with free fatty acids and volatile oxidative by-products and flavour components. Our aim is to keep the natural ingredients in the oil as much as possible (mild conditions). Keeping the temperature usually below $240^{\circ} \mathrm{C}$ and preserve at least $85 \%$ of the original tocopherol content in the finished oil.

Changing from classical chemical refining over to physical refining also changes the formed byproduct and their utilization. The most important difference is the composition of the so-called deodistillate. The deodistillate from chemical refining is used as a raw material by tocopherol (natural Vitamin E) and plant sterol producers. Tocopherols are natural antioxidants, alpha tocopherol is known as Vitamin E. The tocopherol composition of sunflower oil has a great advantage for natural Vitamin E producers, as it contains more than $90 \%$ of alpha tocopherol and only traces of $ß$ and gamma isomers.

Plant sterols have been of great importance in the last years, when it was proved that adding plant sterol to the margarine can reduce the risk of the cardiovascular diseases. Plant sterols increase the good (HDL) cholesterol level in the blood. Worldwide, there is an increasing demand for natural tocopherols and plant sterols used as food additives.

Deodistillate originating from physical refining is not attractive for Vitamin E/sterol producers because it is diluted with free fatty acid (a comparison of the deodistillate composition is shown in figure 6). In the case of sunflower deodistillate the total tocopherol content is only $1 \%-2 \%$ compared to $5 \%-7 \%$ of chemical ones.

The trend to switch to physical refinery and the need to use more and more plant origin tocopherol/sterols initiated different solutions.

One of the solutions is to preconcentrate the deodistillates to reduce the logistic cost. Different processes like double distillation, esterification, transesterification, prior to distillation, have been found suitable in our pilot scale experiments to produce value-added concentrates and parallel pure distilled fatty acids or distilled methylesters as by-products [16].

The other approach is the controlled tocopherol removal/withdrawal during processing. 
New developments in the field of equipment design pre- or post-stripping and packed columns made possible to separate the free fatty acid containing distillates (flashing out the free fatty acid at high temperature) from the tocopherol/sterol containing deodistillates. This is the dual temperature deacidification/deodorization principle, which is highly flexible. One can keep as much tocopherol in the oil as it is possible (premium quality oil) or can distill out more tocopherol and sell it at a good price with only the minimum necessary tocopherol amount retained in the oil. For these, De Smet proposes its Dual-Temperature deodorization, Alfa Laval soft column deodorization or Lurgi prestripper.

\section{CONCLUSION}

Huge capacity sunflower oil physical refining lines are successfully operating in different countries using the developments of the last decades resulting in better processes, more suitable adsorbent, high capacity equipment with really improved performance producing high quality refined sunflower oil in a more economic and environment-friendly way.

\section{REFERENCES}

1. DENISE J (1998). Recent trends in oil processing. OCL, 5: 354.

2. ROHDENBURG M, et al. (1993). Entschleimung-sverfahren. Assignee Krupp European Patent 473895 (1992). US Patent 5, 239096.

3. CLEENWERCK B, et al. (1992). Process for the continuous removal of gum phase from triglycerid oils. Assignee: N.V. Vandermortale European patent. 507363.

4. AALRUST E, et al. (1992). Enzymatisches Verfahren zur Verminderung des Gehaltes an phosphorhaltigen Bestandteilen in pflante u. Herischen Ölen. Assignee: Röhm GmbH European Patent, 513709.

5. JAMIL S, et al. (1995). Procédé de dégommage d'un corps gras et corps gras ainsi obtenu. Assignee: Fractionnement Tirtiaux WO Patent: 95/00609.

6. RIMGERS, et al. (1977). Degumming process for triglyceride oils. Assignee: Unilever US Patent 4, 049686.

7. SANDE, et al. (1989). Method for refining glycerid oils. Assignee: Unilever European Patent, 348004.

8. DIJKSTRA AJ (1986). Process for producing degummed vegetable oils and gums of high phosphatic acid content. Assignee: N.V. Vandemoortele European Patent, 195991.

9. TRANSFELD P (1998). Countercurrent bleaching with electric filtration technique. OCL, 5: 378. 
10. KÖVARI K, et al. (1992). Silica refining of vegetable oils. Poster presented at AOCS World Conference, Budapest.

11. HÉNON G, et al. (1999). Deodorisation of vegetable oils. Part 1: modeling of geometrical isomerization of polyunsaturated fatty acids. JAOCS, 76: 73-81.

12. KÖVARI K, et al. (1997). Kinetics of trans izomer formation during heating. Lecture presented at 22nd Congress of ISF Kuala Lumpur.

13. HÉNON G, et al. (1997). Degradation of a-linolenic acid during heating. JAOCS, 74: 1615.

14. HÉNON G, et al. (1999). Modèle prédictif de l'isomérisation trans des acides gras polyinsaturés au cours de la désodorisation industrielle des huiles. Lecture presented on Journées Chevreul, Pessac.

15. KÖVARI K, et al. (1996). Seed crushing oil refining and environmental problems. Lecture presented at 21st ISF Congress. The Haque (1995). Published: Proceeding p. 655. P.J. Barnes Associates.

16. KÖVARI K, et al. (1998). Method to convert oil refining by-products into value added products. Lecture presented at AOCS Congress, Chicago.

17. Information leaflets of De Smet, Lurgi and Alfa Laval.

Illustrations

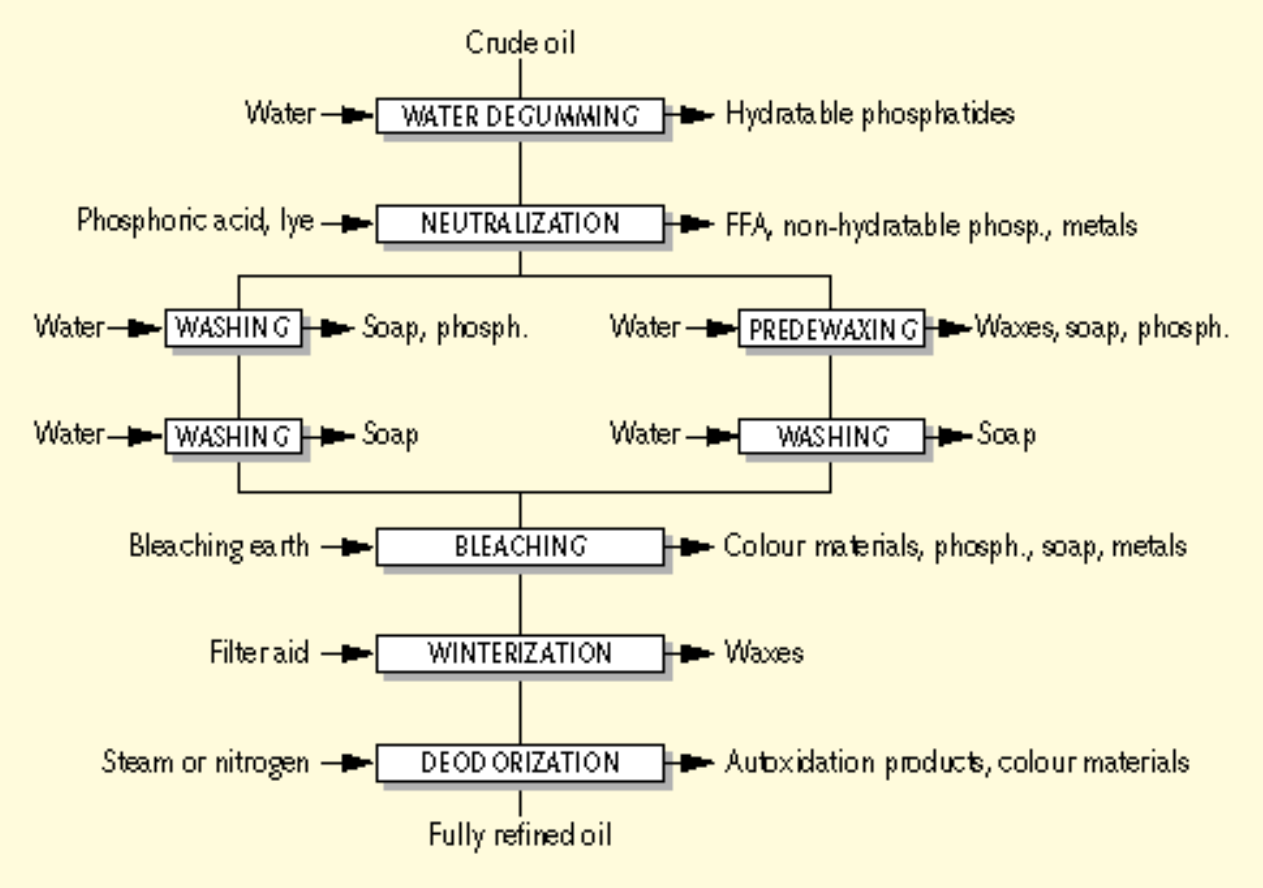

Figure 1. Chemical refining. 


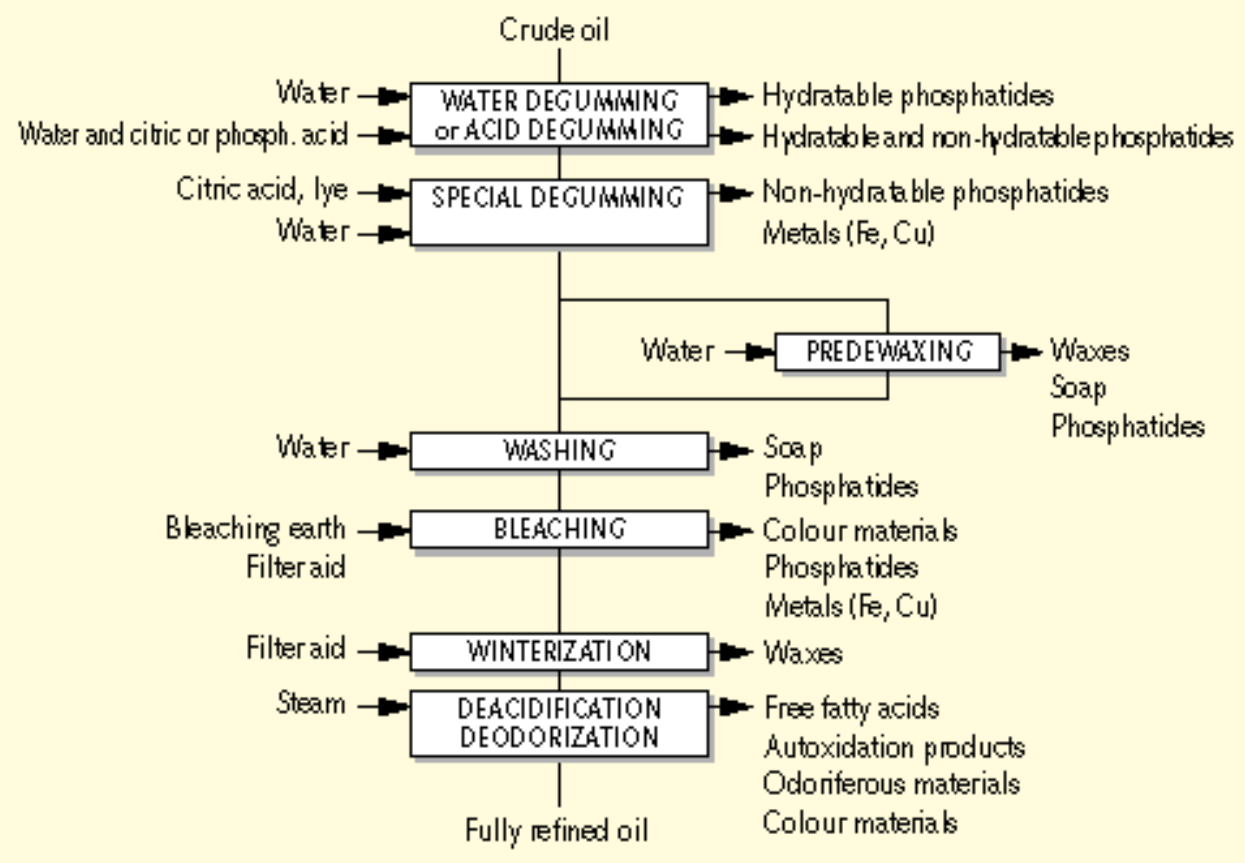

Figure 2. Physical refining.

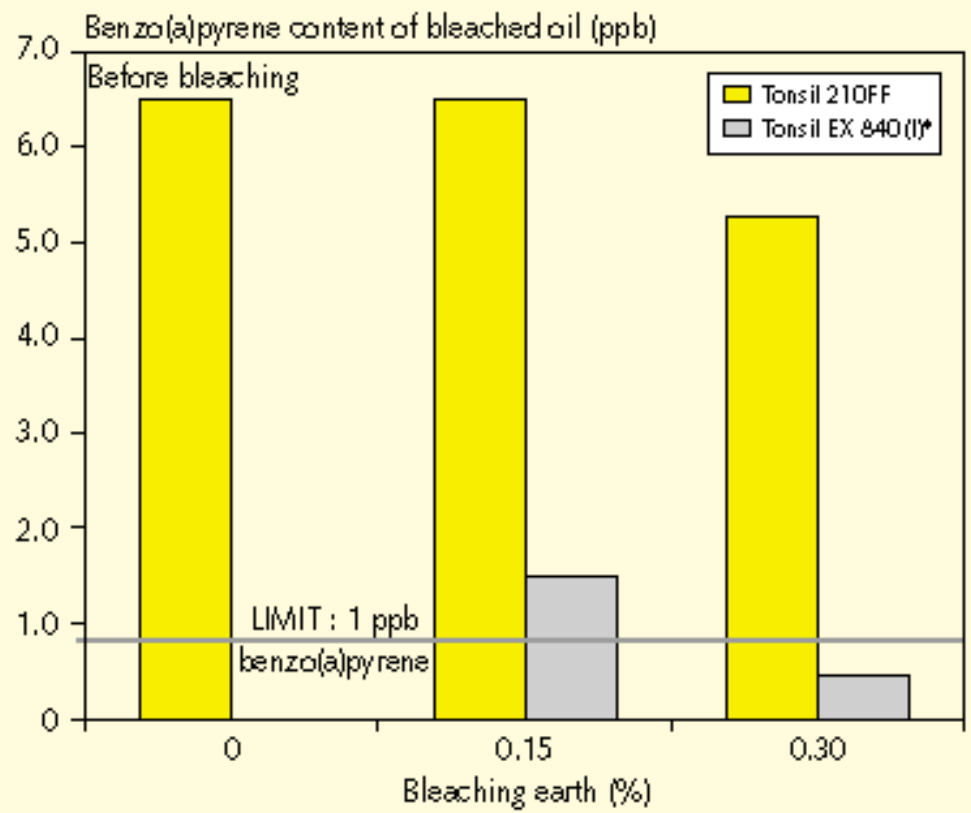

- Mixture of $25 \%$ activated carbon and $75 \%$ activated bleaching earth

Figure 3. Removal of polycyclic aromatic hydrocarbons during bleaching. 
- Linoleic acid

(trans $\mathrm{C} 18: 2)_{\mathrm{t}}=(\text { total } \mathrm{C} 18: 2)_{t=0} *\left(1-10^{-K(L)+t)}\right.$,

Isomerization constant: $\log K_{(L)}=-7,924.95 / T+12.76$

- Linoleic acid

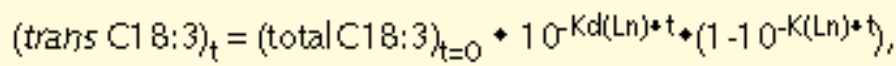

Degradation constant: $\log K_{d(L n)}=-7,503.3 / T+12.12$

Isomerization constant: $\log K_{(L)}=-6,796.63 / T+11.78$

G. Hénon et al. J. Am. Oil Chem. Soc. 76 : 73-81 (1999)

Figure 4. Isomerization of linoleic and linolenic acids.

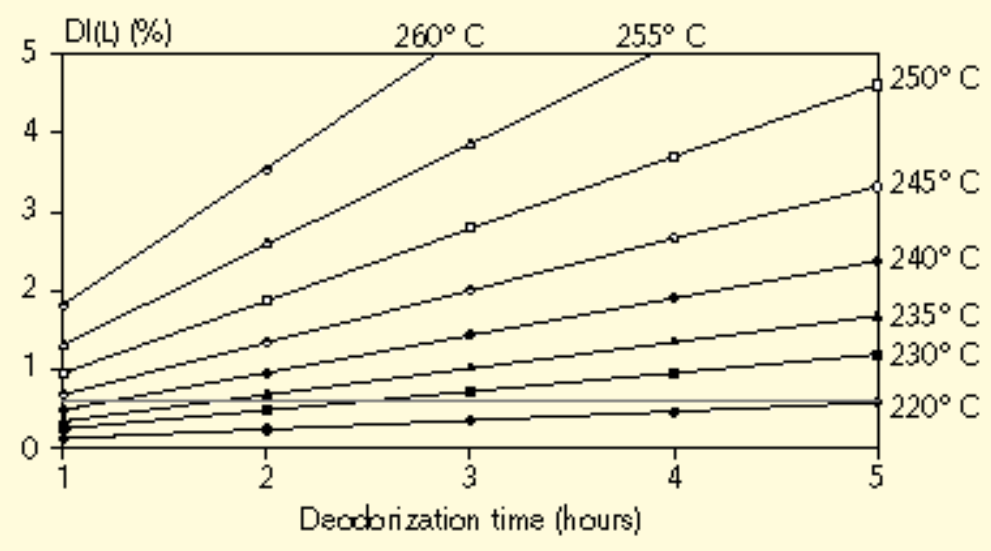

Figure 5. Theoretical calculation for degree of isomerization of linoleic acid. $D I_{(L)}$ at different deodorization conditions. 


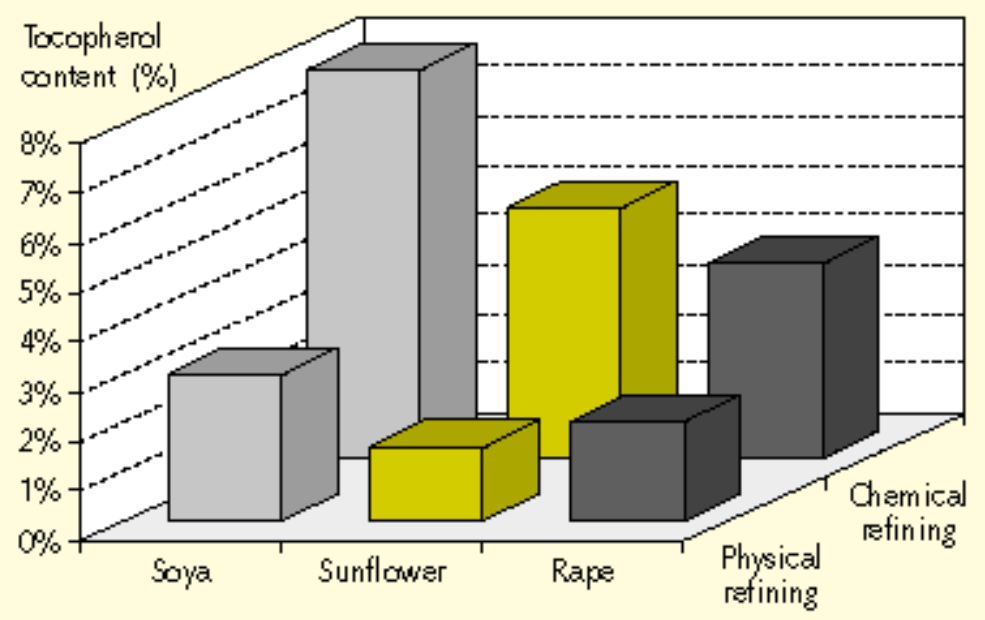

Figure 6. Typical tocopherol content of deodistillate.

\begin{tabular}{|c|c|c|c|c|}
\hline $\begin{array}{l}\text { Patent } \\
\text { owner }\end{array}$ & Process & $\begin{array}{c}\text { Raw } \\
\text { material }\end{array}$ & Core of process & $\begin{array}{l}\text { Residual } \\
\text { ph osphor }\end{array}$ \\
\hline Unilever & \begin{tabular}{|l|} 
Superdegumming \\
Unidegumming
\end{tabular} & $\begin{array}{l}\text { Crude or water } \\
\text { degummed oil } \\
\text { super- } \\
\text { degummed oil }\end{array}$ & $\begin{array}{l}\text { Heating, acid addition, cooling, } \\
\text { holding } \\
\text { Lye addition, cooling, holding }\end{array}$ & $\begin{array}{l}30-50 \mathrm{ppm} \\
<10 \mathrm{ppm}\end{array}$ \\
\hline Vandemoortele & TOP degumm ing & $\begin{array}{l}\text { Crude or water } \\
\text { degummed oil }\end{array}$ & $\begin{array}{l}\text { Heating, acid addition, special dynamic } \\
\text { mixing, lye addition, special two-step- } \\
\text { separation, wa shing, drying }\end{array}$ & $<10 \mathrm{ppm}$ \\
\hline Lurgi & Enzymax process & $\begin{array}{l}\text { Crude or water } \\
\text { degummed oil }\end{array}$ & $\begin{array}{l}\text { Heating, pH adjustement (acid and lye } \\
\text { addition), enzyme addition, holding, } \\
\text { recycling, special separation }\end{array}$ & $<10 \mathrm{ppm}$ \\
\hline Cereol & UF degumming & $\begin{array}{l}\text { Crude or water } \\
\text { degummed oil }\end{array}$ & $\begin{array}{l}\text { Heating, acid addition, lye addition, } \\
\text { cooling, holding, one-step-separation }\end{array}$ & $<10 \mathrm{ppm}$ \\
\hline
\end{tabular}

Table. Existing degumming processes. 